\section{A review of therapies for diabetic macular oedema and rationale for combination therapy}

\begin{abstract}
Diabetic macular oedema (DMO) is responsible for significant visual impairment in diabetic patients. The primary cause of DMO is fluid leakage resulting from increased vascular permeability through contributory anatomical and biochemical changes. These include endothelial cell (EC) death or dysfunction, pericyte loss or dysfunction, thickened basement membrane, loss or dysfunction of glial cells, and loss/change of EC Glycocalyx. The molecular changes include increased reactive oxygen species, pro-inflammatory changes: advanced glycation end products, intracellular adhesion molecule-1, Complement 5-9 deposition and cytokines, which result in increased paracellular permeability, tight junction disruption, and increased transcellular permeability. Laser photocoagulation has been the mainstay of treatment until recently when pharmacological treatments were introduced. The current treatments for DMO target reducing vascular leak in the macula once it has occurred, they do not attempt to treat the underlying pathology. These pharmacological treatments are aimed at antagonising vascular endothelial growth factor (VEGF) or non-VEGF inflammatory pathways, and include intravitreal injections of anti-VEGFs (ranibizumab, aflibercept or bevacizumab) or steroids (fluocinolone, dexamethasone or triamcinolone) as single therapies. The available evidence suggests that each individual treatment modality in DMO does not result in a completely dry macula in most cases. The ideal treatment for DMO should improve vision and improve morphological changes in the macular (eg, reduce macular oedema) for a significant duration, reduced adverse events, reduced treatment burden and costs, and be well tolerated by patients. This review evaluates the individual treatments available as
\end{abstract}

WMK Amoaku, S Saker and EA Stewart

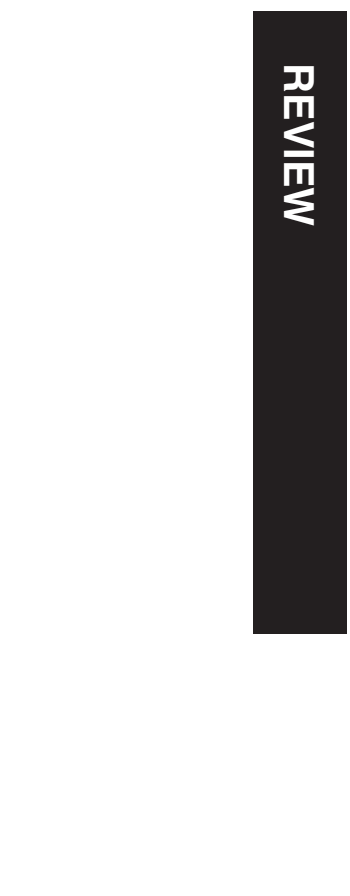

monotherapies, and discusses the rationale and potential for combination therapy in DMO. A comprehensive review of clinical trials related to DMO and their outcomes was completed. Where phase III randomised control trials were available, these were referenced, if not available, phase II trials have been included.

Eye (2015) 29, 1115-1130; doi:10.1038/eye.2015.110; published online 26 June 2015

\section{Introduction}

In 2002, it was reported that diabetes affected 220 million people worldwide, ${ }^{1}$ and anticipated that the prevalence of diabetes will double within the next 10 years. ${ }^{2}$ More recent estimates indicate that the prevalence of diabetes in adults (aged 20-79 years) worldwide was 382 million people in 2012, and that this would likely increase to 592 million in 2035. ${ }^{3}$

Diabetic retinopathy (DR) has been extensively studied over the years, and its incidence correlates with poor glycaemic control and hyperlipidaemia. ${ }^{4,5}$ Diabetic choroidopathy is a less well-studied entity, and is thought to occur in the advanced stages of diabetic eye disease. ${ }^{6-9}$ As such, the retinal and choroidal vascular beds seem to be affected differently by diabetes. Diabetes and hyperglycaemia have obvious effects on intraocular vascular endothelial cell (EC) permeability, adhesion to leukocytes, as well as angiogenesis. ${ }^{10-12}$ These alterations result in increased vascular leakage (increased permeability), vascular occlusions, ischaemia, and angiogenesis. ${ }^{13,14}$ However, the exact mechanisms underlying these changes are not fully understood, and require further elucidation.
Academic Ophthalmology, Division of Clinical Neuroscience, University of Nottingham, Queen's

Medical Centre,

Nottingham, UK

Correspondence: Ophthalmology, Division of Clinical Neuroscience, University of Nottingham, Queen's Medical Centre, B Floor, Eye and ENT Building, Nottingham, NG7 2UH, UK

Tel: +44 (0)1159709796;

Fax: +44 (0)1159709963.

E-mail: winfried.amoaku@ nottingham.ac.uk

Received: 8 January 2015 Accepted in revised form: 6 May 2015

Published online: 26 June 2015
WMK Amoaku, Academic 


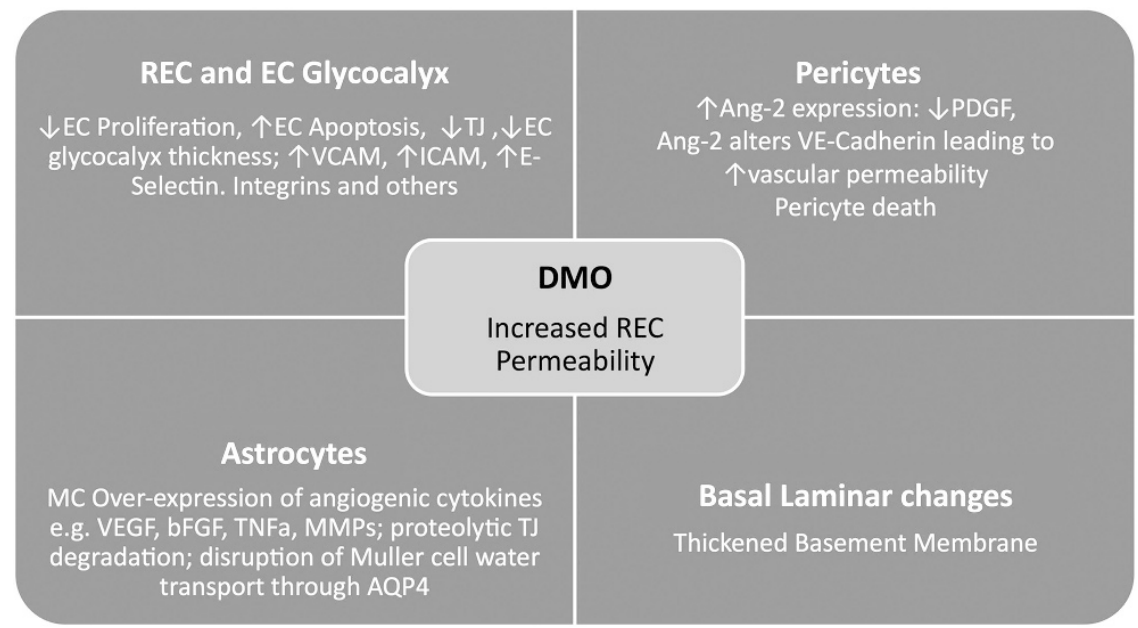

Figure 1 Pathogenesis of diabetic vasculopathy. DMO, diabetic macular oedema; Ang-2, Angiopoietin-2; EC, endothelial cell; ICAM, intercellular adhesion molecule; IP, interferon-induced protein; MMP, metallic metalloproteinase; VEGF, vascular endothelial growth factor; VE, vascular endothelial; PDGF, platelet-derived growth factor; TJ, tight junction, bFGF, basic fibroblast growth factor.

Diabetic macular oedema (DMO) is responsible for significant visual impairment in diabetic patients. ${ }^{1,2,15,16}$ In the retina, leakage is due to increased permeability that occurs at the retinal 'neurovascular' unit, which consists of single layer of tightly adherent ECs, basal lamina, surrounding pericytes, astrocytes, and microglia leading to increased EC trans- or paracellular permeability, as summarised in the recent review by Klaassen et al. ${ }^{17}$ There are contributory anatomical and biochemical changes that are interlinked (Figure 1). The anatomic changes include EC damage - death or dysfunction, pericyte loss or dysfunction, thickened basement membrane, loss or dysfunction of glial cells, and loss/change of EC Glycocalyx. The molecular changes include increased reactive oxygen species, pro-inflammatory changes: advanced glycation end products, intracellular adhesion molecule-1 (ICAM-1), Complement 5-9 (C5-9) deposition, cytokines, which result in increased paracellular permeability-small molecules and water: tight junction (TJ) disruption-and increased transcellular permeability-large molecules and water: caveolar transport, aquaporins, plasmalemmal vesicle-associated protein. The increased intraretinal fluid leads to progressive retinal dysfunction (see Klaassen et al ${ }^{17}$ review). The contributions of the choroidal vasculature to the clinical disease of DR are less well understood, but again will be largely contributed to by the choroidal EC (CEC) alterations. ${ }^{6-9}$ It is known that retinal vascular leakage in $\mathrm{DMO}$ is contributed to by vascular endothelial growth factor (VEGF) upregulation as well as non-VEGFdependent inflammatory pathways, so that chronic subclinical inflammation is important in the pathogenesis of DR. ${ }^{18-28}$ An early event in the pathogenesis of diabetic vasculopathy is leukocyte adherence to retinal vascular endothelium, resulting in EC death, vascular leakage, and capillary closure ${ }^{18}$ (Figure 2 ).

The current treatments for DMO at reducing vascular leak in the macula once it has occurred, and aim for a dry macular subsequently. No attempt is made at addressing the underlying pathology, although it is possible that some of these treatments may alter retinal function in other ways (such as neurodegeneration) in addition to reducing vascular leakage.

This review evaluates the individual treatments available, and discusses the rationale and potential for combination therapy in DMO.

\section{Laser photocoagulation}

Laser photocoagulation was the recommended treatment for DMO for several years. ${ }^{29,30}$ The exact mechanisms of action of laser photocoagulation in reducing oedema in DMO are unknown. Plausible mechanisms include destruction of high-oxygen consuming photoreceptors, increased oxygenation of the retina through diffusion from the choroid, restoration of new retinal pigment epithelium (RPE) barrier, production of cytokines including transforming growth factor- $\beta$ and pigment epithelium-derived factor from the stimulated RPE as discussed in the review by Bhagat et al. ${ }^{16}$ In the early treatment diabetic retinopathy study (ETDRS), DMO eyes treated with laser had lower rates of visual loss compared with control group ( $12 \%$ vs $24 \%$ at 3 years). This benefit was only noticeable in eyes with clinically significant DMO.$^{29,30}$ In eyes with diffuse DMO, response to grid laser photocoagulation was of limited benefit, with only $15 \%$ showing a visual improvement, $24 \%$ developing visual deterioration, and $61 \%$ unchanged. ${ }^{31}$ The average 


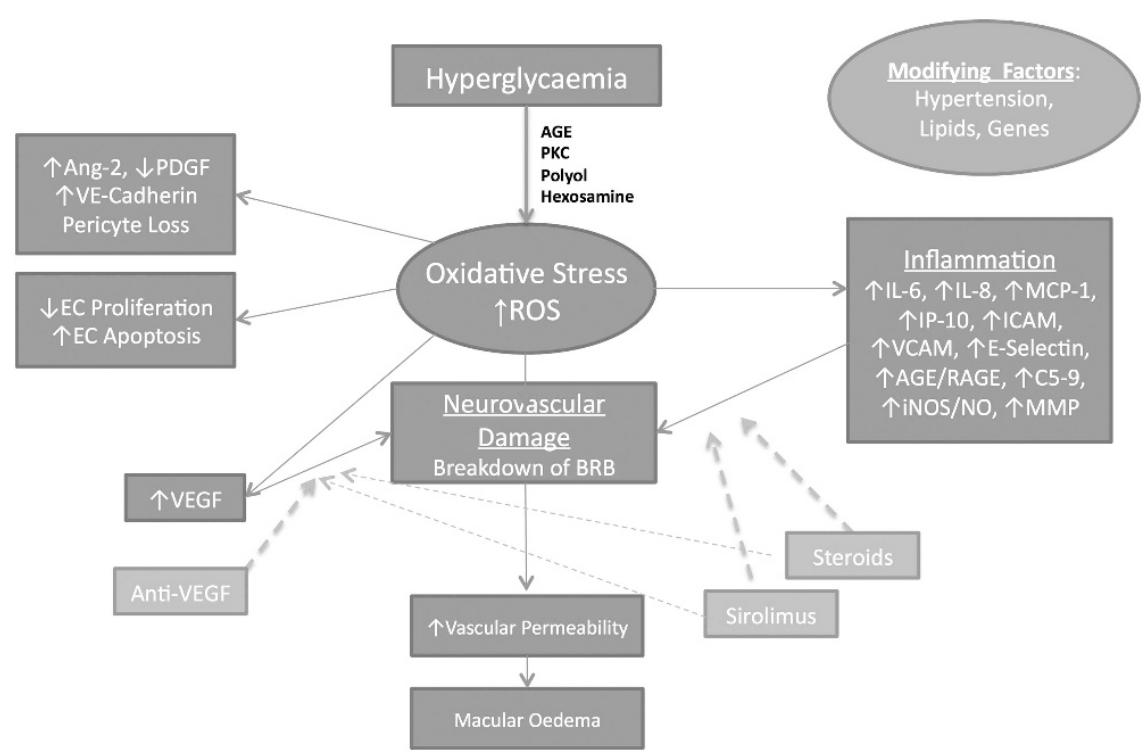

Figure 2 Pathophysiology and treatment mechanisms in diabetic macular oedema (DMO). AGE, advanced glycation products; Ang-2, Angiopoietin-2; EC, endothelial cell; C, complement; ICAM, intercellular adhesion molecule; IL, interleukin; MCP, monocyte chemotactic protein; IP, interferon-induced protein; MMP, metallic metalloproteinase; NO, nitric oxide; NOS, nitric oxide synthase; RAGE, receptor for advanced glycation products; VEGF, vascular endothelial growth factor; VE, vascular endothelial; ROS, reactive oxygen species; PDGF, platelet-derived growth factor; PKC, protein kinase C; BRB, blood-retinal barrier.

best corrected visual acuity (BCVA) change in lasertreated eyes in the diabetic retinopathy clinical research network (DRCRnet) and RESTORE (ranibizumab monotherapy or combined with laser vs laser monotherapy for DMO) studies were +2.7 to +3.2 letters at 12 months, and the fovea remained thickened in a large proportion of the laser-treated eyes. Although effective in some cases of DMO, ETDRS protocol photocoagulation may require placement of burns close to the centre of the macula. Over time, laser burns may develop into areas of progressive RPE and neuroretinal atrophy that become larger than the original laser spot size and encroach upon fixation, or subretinal membranes may occur. ${ }^{32,33}$

Photocoagulation for DMO may be associated with loss of central vision, central scotomas, and decreased colour vision. In an attempt to reduce these adverse effects, many retinal specialists now treat with burns that are lighter and less intense than originally specified in the ETDRS (modified-ETDRS technique). ${ }^{34}$ In the alternative approach of mild macular grid laser, mild, widely spaced burns are applied throughout the macula, avoiding the foveal region. By design, some burns could be placed in clinically normal retina if the entire retina was not abnormally thickened, including areas within the macula that are relatively distant from the area of thickening. ${ }^{34}$ As such, laser photocoagulation is not advised in eyes where the leakage is close to the fovea and when the oedema is centre involving.

Subthreshold laser photocoagulation has recently been suggested as a better alternative in the treatment of DMO as the collateral damage to the retina-choroid complex is limited. ${ }^{16,35}$ That is because subthreshold laser does not destroy the RPE on account of the much shorter duration. The role of subthreshold laser therapy in DMO has yet to be widely taken up, and requires further evaluation.

\section{Pharmacologic treatments}

Several pharmacologic agents are now available for the treatment of DMO including anti-VEGF agents ${ }^{36-41}$ and corticosteroids. ${ }^{36,42-48}$ These treatments are summarised in Table 1. These treatments are particularly useful in eyes with centre-involving DMO. Targeting VEGF has resulted in the use of anti-VEGFs, including pegaptanib, ranibizumab, aflibercept, and bevacizumab, in the treatment of DMO. ${ }^{36-41,43}$ Several clinical studies have investigated the efficacy of steroids, such as triamcinolone, fluocinolone, and dexamethasone, in the treatment of DMO. ${ }^{13,42,46-51}$ Corticosteroids may reduce DMO by targeting the non-VEGF-dependent inflammatory pathways including blockage of the arachidonic acid pathway (reduction of prostaglandin synthesis), and inhibition of the release of proinflammatory mediators, including VEGF. This may be through modulation of EC TJ molecules. ${ }^{19}$

\section{Ranibizumab}

In the RISE and RIDE Study of two multicentre doubleblind controlled trials, of intravitreal ranibizumab 


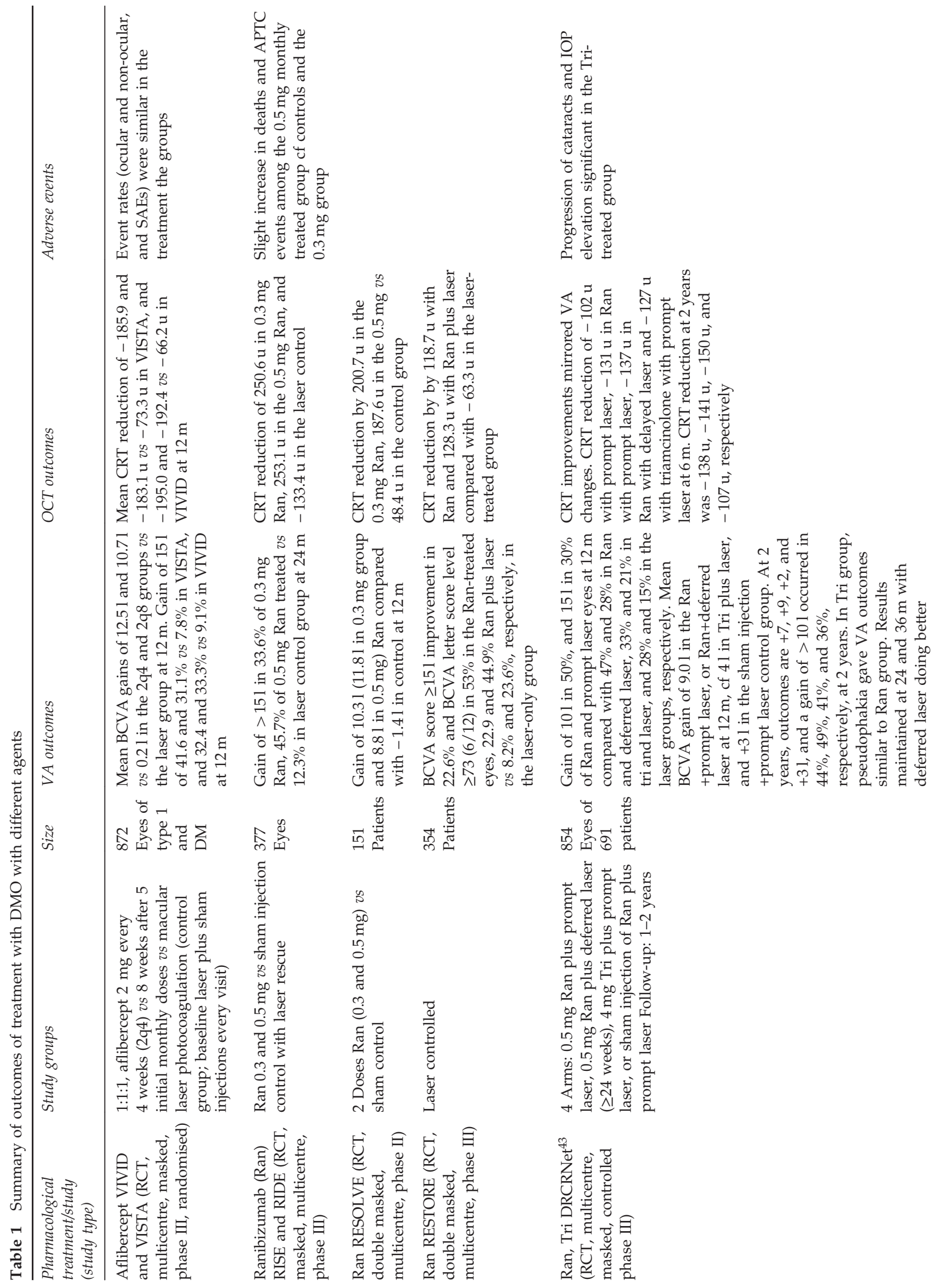




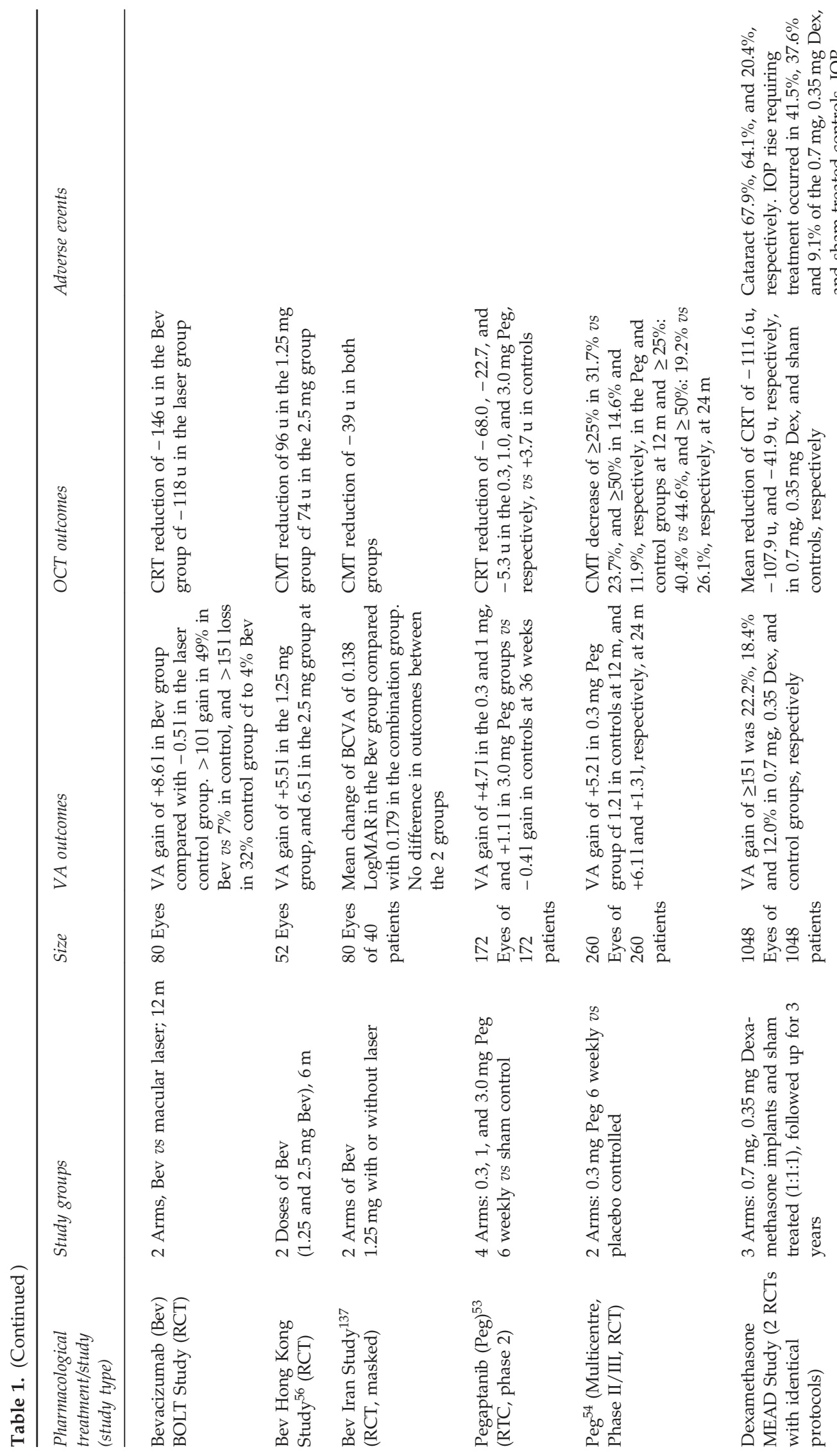


(0.3 and 0.5 mg; Lucentis, Genentech, South San Francisco, CA, USA/Novartis, Basel, Switzerland) was compared with laser photocoagulation, $45.7 \%$ in the ranibizumab group gained $>15$-letter improvement in visual acuity (VA) at 24 months compared with $12.3 \%$ in the laser-treated group. ${ }^{39}$ There was a signal for increased deaths and acute thrombolytic events (as per the Antiplatelet Trialists' Collaboration criteria) in patients treated with the monthly $0.5 \mathrm{mg}$ ranibizumab compared with the laser-treated group. However, these differences were not statistically significant, and have not been repeated in related studies. In RESOLVE, a 12-month, multicentre, sham-controlled, double-masked study of eyes with centre involving DMO (age 18 years, type 1 or 2 diabetes, central retinal thickness (CRT) $300 \mu \mathrm{m}$ ), patients received 3 monthly injections of ranibizumab followed by rescue laser or prn ranibizumab. ${ }^{37}$ BCVA improved from baseline by a mean of $10.3 \pm 9.1$ letters with ranibizumab and declined by $1.4 \pm 14.2$ letters with sham $(P<0.0001)$. A mean reduction of CRT of $194.2 \pm 135.1 \mu \mathrm{m}$ with ranibizumab and $48.4 \pm 153.4 \mu \mathrm{m}$ with sham $(P<0.0001)$ was achieved. Similarly, the RESTORE Study ${ }^{38}$ demonstrated superiority of the $0.5 \mathrm{mg}$ ranibizumab monotherapy group or in combination with laser photocoagulation compared laser alone, with a mean of seven injections over 12 months. There was a reduction in CRT on optical coherence tomography (OCT) by $-118.7 \mathrm{u}$ with ranibizumab compared with $-63.3 \mathrm{u}$ in the lasertreated group. ${ }^{38}$ In the DRCR.net Study (Protocol I), 50\% of eyes treated with intravitreal ranibizumab showed $>10$-letter improvement at 24 weeks compared with baseline; 30\% gained >15 letters. ${ }^{43}$ Results were similar whether laser photocoagulation was prompt or deferred for $>24$ weeks. The results were maintained at 24 and 36 months, although eyes with deferred laser doing better in the longer term (2.9 letters better at 36 months). ${ }^{36,43,52}$ These VA changes were associated with parallel reductions in CRT as measured with OCT. ${ }^{36}$

\section{Aflibercept}

The VIVID and VISTA Studies are two parallel studies that compared the efficacy and safety of aflibercept (Eylea, Bayer) given every 4 or 8 weeks after an initial monthly dosing for 5 months with focal laser photocoagulation at 52 weeks. ${ }^{41}$ The results showed that there was significant superiority of aflibercept in anatomical and functional end points when compared with laser. The efficacy of the 8 weekly dosing was similar that of 4 weekly dosing. The mean BCVA improvement at week 52 was 12.5 and 10.7 letters in the 4 weekly and 8 weekly treated groups, respectively, compared with 0.2 letters in the laser photocoagulation group of VISTA. In the VIVID Group, the corresponding improvements were 
10.5, 10.7, and 1.2 letters, respectively. ${ }^{41}$ The mean reductions in CRT were 185.9 and 183.1 compared with $73.3 \mu \mathrm{m}(P<0.0001)$ in VISTA and 195.0 and 192.4 compared with $66.2 \mu \mathrm{m}$ in VIVID. The proportion of eyes gaining 15 letters or more were $41.6 \%$ and $31.1 \%$ compared with $7.8 \%$ in VISTA, and $32.4 \%$ and $33.3 \%$ compared with $9.1 \%$ in VIVID $(P<0.0001) .{ }^{41}$

\section{Pegaptanib}

Two different randomised controlled studies evaluated the efficacy of pegaptanib (Macugen, Eyetech Pharma, New York, NY, USA/Pfizer, New York, NY, USA) in DMO. In the Cunningham study (a phase II study), the 0.3 and $1 \mathrm{mg}$ injection groups had a better visual outcome with a gain of +4.7 letters at 6 months. ${ }^{53}$ In another study (Phase II/III), Sultan et al ${ }^{54}$ compared outcomes with $0.3 \mathrm{mg}$ pegaptanib with sham. The BCVA at 2 years was significantly better in the pegaptanib-treated group (gain of +6.1 letters) compared with sham (+1.3 letters). However, there was no difference in proportions of eyes gaining 10 letters or more (38.3\% pegaptanib vs 30.0\% sham). ${ }^{54}$ Pegaptanib has not received marketing authorisation for the treatment of DMO in the European Union.

\section{Bevacizumab}

Bevacizumab (Avastin, Roche/Genentech), which is unlicensed for any intraocular indication, has also been used in the treatment of DMO. The BOLT study reported a 10-letter improvement in BCVA at 24 months for eyes treated with bevacizumab compared with $7 \%$ in the multiple focal laser photocoagulation group. ${ }^{55}$ Similarly, there was an 8.6-letter improvement in the bevacizumabtreated group compared with -0.5 letters in the laser group. More significantly, there was visual loss of more than 15 letters or more in the laser compared with the bevacizumab group. ${ }^{55}$ Lam et al ${ }^{56}$ compared two different doses of bevacizumab (1.25 and $2.5 \mathrm{mg})$ in DMO and found no difference in outcomes at 6 months.

\section{Triamcinolone}

Triamcinolone reduces macular oedema (in DMO), although the visual outcome is limited, and there is significant association with elevated intraocular pressure (IOP) and cataract formation. ${ }^{57-59}$ In addition, injections needed to be repeated at variable intervals. There was no evidence of long-term benefits of intravitreal injection of triamcinolone as treatment for DMO. ${ }^{5,59}$ The commonly available Kenalog (Squibb) preparation of triamcinolone is unlicensed for intraocular administration. The preservative-free preparations of triamcinolone are not freely available. Results from the Gillies et $a l^{60}$ study in Australia were not very different from those in the DRCNnet studies.

\section{Fluocinolone}

Fluocinolone $0.59 \mu \mathrm{g}$ implant (Retisert, Bausch and Lomb, Rochester, NY, USA) resulted in an overall VA improvement of $\geq 3$ lines (compared with sham injection/ standard of care (SOC)) in $16.8 \%$ of implanted eyes at 6 months $(P=0.0012)$, in $16.4 \%$ at 1 year $(P=0.1191)$, in $31.8 \%$ at 2 years $(P=0.0016 ; \mathrm{SOC}, 9.3 \%)$; and in $31.1 \%$ at 3 years $(P=0.1566$; SOC, $20.0 \%)$. However, there was a significant increase in cataracts and IOP. ${ }^{46}$

With a different design of implant, fluocinolone acetonide implant (Iluvien, Alimera Sciences, Alpharetta, GA, USA) was compared with sham injection (with laser rescue) in patients with $\mathrm{DMO}$ in order to evaluate the safety and efficacy of an intravitreal insert of fluocinolone acetonide for the treatment of DMO. Two doses of 0.2 and $0.5 \mu \mathrm{g}$ of fluocinolone implant were compared with the sham implant group for 36 months. The primary outcome was the difference in the percentage of patients with BCVA improvement by $\geq 15$ letters from baseline at month 24 between the treatment was 28.7 and 28.6 in the low- and high-dose insert groups, respectively, compared with 16.2 in the sham group $(P=0.002)$. The mean improvement in BCVA letter score between baseline and month 24 was 4.4 and 5.4 in the 0.2 and $0.5 \mu$ groups. ${ }^{47}$ There was a significant reduction in macular oedema. Further analysis suggested that fluocinolone was more effective in eyes with long-standing DMO, where chronic inflammation was more important than the VEGFmediated oedema. The fluocinolone implant lasts up to 2 years. However, there was a significant increase in the incidence of IOP elevation and cataracts. ${ }^{47}$

\section{Dexamethasone}

In a prospective multicentre open label, 26-week study of 55 eyes to evaluate the safety and efficacy of dexamethasone intravitreal implant (Ozurdex, Allergan, Irvine, TX, USA) $0.7 \mathrm{mg}$ in the treatment of DMO in vitrectomized eyes, there was a significant improvement in BCVA by 6.0 and 3.0 letters at 8 and 26 weeks, respectively, from baseline, and vascular leakage as shown by a reduction from baseline CRT $(403 \mu \mathrm{m})$ of a mean $-156 \mu \mathrm{m}$ at week $8(P<0.001)$ and $-39 \mu \mathrm{m}(-65$, $-13 \mu \mathrm{m})$ at week $26(P=0.004)$. At week $8,30.4 \%$ of patients had gained $\geq 10$ letters in BVCA. ${ }^{44}$ In their most recent report, Boyer et al ${ }^{45}$ have evaluated the 3-year outcomes of treatment of DMO, and suggest that the dexamethasone implant was efficacious in the treatment of DMO over the medium term. The mean number of 
treatments given over 3 years was $4.1,4.4$, and 3.3 with dexamethasone implant $0.7 \mathrm{mg}$, dexamethasone implant $0.35 \mathrm{mg}$, and sham, respectively. The percentage of patients with $\geq 15$-letter improvement in BCVA from baseline at study end was greater with dexamethasone implant $0.7 \mathrm{mg}(22.2 \%)$ and dexamethasone implant $0.35 \mathrm{mg}(18.4 \%)$ than sham $(12.0 \%$; $P<0.018)$. However, treatments needed to be given more frequently than 6 monthly, probably at 3-4 months intervals, to maintain a dry macula and retain good visual function. ${ }^{45}$ The cataract-related adverse event rates in phakic eyes were $67.9 \%, 64.1 \%$, and $20.4 \%$ in the dexamethasone implants of $0.7 \mathrm{mg}, 0.35 \mathrm{mg}$, and sham groups, respectively. IOP rises associated with the dexamethasone implant were usually controlled with medication.

Gillies et $a l^{60}$ recently reported that dexamethasone implant (Ozurdex, Allergan) was as efficacious as bevacizumab in reducing $\mathrm{DMO}$, although progressive lens opacities may result in visual loss in the Ozurdextreated group compared with those treated with bevacizumab.

\section{Potential treatments}

\section{Angiopoietin (Ang)-2 blockage}

Ang-2 is another cytokine with inflammatory and angiogenic properties that is expressed by EC. Ang-2 levels are regulated at the level of transcription by different cytokines including VEGF, as well as hypoxia and high-glucose levels, ${ }^{61-64}$ and stored in Weibel-Palade bodies before rapid release. ${ }^{65}$ It is elevated in eyes with clinically significant $\mathrm{DMO}^{66-68}$ as well as proliferative DR (PDR), ${ }^{69,70}$ and is thought to induce loss of vascular endothelial (VE)-cadherin through phosphorylation. ${ }^{71}$ Ang-2 may act by exerting a permissive role for supplementing the action of other pro-inflammatory cytokines $^{72}$ through sensitisation of ECs to tumour necrosis factor (TNF)- $\alpha$ and subsequent expression of ICAM-1. Similarly, in the presence of VEGF, Ang-2 increases vascular permeability. ${ }^{61}$ Recently, You et al ${ }^{73}$ have reported that pan-retinal laser photocoagulation reduced the serum levels of Ang-2 and VEGF in diabetic patients with PDR compared with the significantly elevated pre-treatment levels. Another study ${ }^{74}$ showed that the changes in serum VEGF and Ang-2 following laser photocoagulation were not significant. It has been suggested that benfotiamine, a vitamin B1 derivative may block three major pathways of hyperglycaemia damage and prevent experimental DR. ${ }^{75}$ Yao et al ${ }^{64}$ have suggested that high glucose increased Ang-2 transcription through methoxyglyoxal modifications. Benfotiamine has also been reported to have anti-inflammatory effects. ${ }^{76,77}$ Ang-2 is not expressed by pericytes; pericytes express
Ang-1 (and not Ang-2), which promote EC survival signalling, maintenance of endothelial barrier and vascular maturation and quiescence ${ }^{78-81}$ and reduces VEGF-stimulated leukocyte adhesion to ECs. ${ }^{82}$ Taurine has been reported to inhibit high glucose-induced apoptosis in retinal pericytes through increased Tie-2 expression and downregulation of Ang-2. ${ }^{83}$

\section{Sirolimus}

Sirolimus (rapamycin), a macrolide antibiotic, has immunosuppressive and anti-proliferative activities through its inhibition of the mammalian target of rapamycin (mTOR). ${ }^{84}$ Sirolimus, through its inhibition of mTOR, inhibits VEGF expression and signalling, and downregulates HIF-1A. ${ }^{85-90}$ In addition, sirolimus has been shown to inhibit VEGF-induced microvascular permeability, and reduces protein kinase C (PKC) activity, ${ }^{85-91}$ as well as reduces the expression of inflammatory cytokines. ${ }^{92,93}$ Recently, a phase 1 study of subconjunctival and intravitreal sirolimus in DMO was reported by Dugel et al. ${ }^{94}$ No non-ocular adverse events were noted, and the systemic exposure to sirolimus was low. There were no serious ocular adverse events reported. A median BCVA improvement of 4.0 letters was noted at day 14 and maintained for 90 days, associated with a reduction in the CRT of $-33 \mathrm{u}$ at day 14 and $-68.3 \mathrm{u}$ at day 90. Similarly, Krishnadev et al ${ }^{95}$ in their phase I/II study reported sirolimus to be safe when administered subconjunctivally, although the treatment effect was variable. Progress in the development of sirolimus formulations for intraocular delivery (DE-109, Santen Pharma, Osaka, Japan) is encouraging.

\section{Combination therapy}

\section{Scientific basis}

The available evidence suggests that each individual treatment modality in DMO does not result in a completely dry macula in most cases. Furthermore, it takes a while to achieve a dry macula in most cases, requiring frequent treatments. The ideal treatment for DMO should improve vision and improve morphological changes in the macular (eg, reduce macular oedema) for a significant duration, reduced adverse events, reduce treatment burden and costs, and be well tolerated by patients.

It is known that retinal vascular leakage in DMO is contributed to by VEGF upregulation and non-VEGFdependent inflammatory pathways, which may be chronic and subclinical. ${ }^{18-28}$ Accumulating evidence also suggests that chronic subclinical inflammation has an important role in the pathogenesis of DR. An early event 
in the pathogenesis of diabetic vasculopathy is leukocyte adherence to retinal vascular endothelium, resulting in EC death, vascular leakage, and capillary closure. ${ }^{18}$

Clinical evidence indicates that DMO results from breakdown of the inner blood-retinal barrier, ${ }^{96}$ which is maintained by EC TJ complexes. ${ }^{97}$ TJ proteins include occludins, claudins, and junctional adhesion molecules (JAMs), transmembrane molecules, which interact with intracellular molecules including zonula occludens (ZO) and cingulin. Adherens junctions are formed by VE-Cadherin, which promotes calcium-dependent homophilic cell to cell contacts, and interact intracellularly with actin through catenins. Dejana et al ${ }^{98}$ have reported that the principal TJ proteins found in retinal ECs (RECs) are occludin and claudin-5. Phosphorylation of occludin and ZO1 contribute to the dysregulation of EC paracellular permeability. ${ }^{99}$ It has been suggested that the hyper-permeability induced by diabetes and hyperglycaemia is VEGF mediated. ${ }^{100,101}$ VEGF-A is thought to be the main factor responsible for increased retinal vascular permeability as upregulation of it results in phosphorylation of TJ proteins (occludin and ZO) and their disassembly. ${ }^{102,103}$ Exposure of RECs to hyperglycaemia has also been reported to result in increased MMP-9 levels, which lead to active proteolytic degradation of EC TJs especially occludin. ${ }^{104}$ Mukarami et al ${ }^{105}$ and Felinski et al ${ }^{101}$ have attempted to elucidate the mechanisms of VEGF enhancement of vascular permeability. Other factors including $\mathrm{TNF} \alpha$ and interleukin (IL)-1B, ${ }^{106}$ nuclear factor- $\kappa \mathrm{B}(\mathrm{NF}-\kappa \mathrm{B})$ receptor activator, $^{21,22}$ hepatocyte growth factor (HGF), ${ }^{23}$ and the accumulation of advanced glycation end products ${ }^{20}$ are known to induce vascular leakage independent of VEGF-A. Adhesion molecules such as CD $44^{24,25}$ may also contribute significantly to microvascular occlusions and angiogenesis.

JAMs also signal to cytoskeleton-associated proteins, as well as recruiting cellular polarity proteins. The preferential expression of different TJ and adherens junction molecules in different vascular beds may explain their specific physiologic functions, for example, the high expression of JAM-A in the blood-brain barrier (bloodretinal barrier), ${ }^{107}$ and the relative high expression of JAM-A in the liver compared with its minimal expression of JAM-B and C, substitution or redundancy. ${ }^{108}$ JAM-C is highly expressed in inter-EC junctions in lymph nodes. ${ }^{109}$ Different JAMs including JAM-A, $-\mathrm{B},-\mathrm{C}$ are altered in diabetes and hyperglycaemia. ${ }^{110}$ Furthermore, different capillary beds may respond differently to different stimulatory or inhibitory factors. ${ }^{111}$ Similarly, they may differ in their basal and $\mathrm{TNF} \alpha$-regulated expression of adhesion molecules and cytokines. ${ }^{112}$ This is supported by the observation that although DR is a microvascular disease microangiopathy does not seem to have a major pathogenic role in the cerebral complications of diabetes and the blood--brain barrier is not as susceptible to hyperglycaemia as the retinal microvasculature. ${ }^{113}$

It has been reported that hyperglycaemia can stimulate both NF- $\kappa$ B- and PKC-dependent pathways thus upregulating endothelial adhesion molecules, such as ICAM-1 (CD54) or E-Selectin (CD62E), ${ }^{114-116}$ vascular cell adhesion molecule-1 (CD106), ${ }^{117}$ and platelet endothelial cell adhesion molecule (CD31), in ECs. ICAM-1 upregulation is thought to be VEGF dependent, whereas P- and E-Selectin are not. ${ }^{118}$ Vitreous levels of several inflammatory cytokines (including IL-6, IL-8, and monocyte chemotactic protein (MCP)-1) are increased in eyes with DMO and PDR. ${ }^{119}$ In other studies, Funatsu et al ${ }^{120-122}$ have reported significant elevations of VEGF, ICAM-1, IL-6, MCP-1, and pigment epithelium-derived factor, which correlated with retinal vascular permeability changes. In addition to this pathway, stimulation of 6-N-acetyl glucosaminyl-transferase in leukocyte can result in more modification of glycans on its surface thus inducing leukocyte rolling interactions to endothelial selectins. ${ }^{123-125}$

Nehme and Edelman ${ }^{126}$ have reported that hyperglycaemia, $\mathrm{TNF} \alpha$, and IL-1 induce an inflammatory phenotype in human retinal perictyes, characterized by hypersecretion of inflammatory and angiogenic mediators. No such change was noted in the retinal microvascular ECs in this study. Dexamethasone at various potencies blocked hypersecretion of several proteins in pericytes. ${ }^{126}$ It was further suggested that corticosteroids may inhibit PLA2 and downstream products, for example, prostaglandins and leukotrienes, as well as inhibit adhesion signalling pathway components, including ICAM-1, IL-6, VEGF-A, and stromal cell-derived factor-1, which are involved in vascular permeability and leucocytosis (inflammation). ${ }^{127}$ Steroids may also inhibit TJ disassembly. Further elucidation of the cellular mechanisms underlying increased permeability in diabetes and hyperglycaemia, and the effects of different pharmacologic agents and their interactions is required.

Corticosteroids have significant effects on RECs. ${ }^{101,128}$ It has been suggested that steroids may act by both suppressing inflammation and by directly affecting the ECs by regulating phosphorylation, organisation, and content of TJ proteins. ${ }^{101}$ Felinski et al ${ }^{128}$ have reported that glucocorticoid treatment of primary RECs increases content of the TJ proteins occludin and claudin-5, in parallel with an increase in barrier properties of endothelial monolayers, therefore restoring endothelial paracellular permeability. However, the exact mechanisms of action are poorly understood.

Microarray analysis studies in our laboratory have determined that occludin and claudin-5 gene expression 
was higher in RECs than CECs under normal glucose culture conditions. ${ }^{110}$ We have further determined that there are differences in HGF expression between RECs and CECs, as well as c-Met (the HGF receptor). Specifically, CEC secrete HGF at higher levels than REC. ${ }^{129}$ These results would support the concept that CEC and REC behave differently under hyperglycaemia, and may explain, at least in part, some of the clinical differences observed in the frequencies/prevalences of DR and choroidopathy. ${ }^{6-9}$ Western blotting indicated that claudin-5 protein expression was also higher in RECs, whereas JAM-A and C and VE-Cadherin levels were similar. ${ }^{110}$ High-glucose conditions (equivalent to hyperglycaemia) significantly increased the permeability in both REC and CEC monolayers, although the increase was higher for RECs. ${ }^{110}$ In RECs exposed to high-glucose claudin-5, occludin, and JAM-A were found to be reduced, and JAM-C increased, whereas the expression of VE-Cadherin was relatively unchanged when evaluated with western blotting, immunofluorescence, and qPCR.

Recent studies have reported that there are significant changes in the cytokine profile in DMO. The elevated cytokines include VEGF, MCP-1, IL-6, IL-8, interferon $\gamma$-induced protein-10. ${ }^{119,130-132}$ Funatsu et al ${ }^{120-122}$ have also previously reported increased levels of ICAM-1, IL-6, Angiotensin II, and VEGF in DR and DMO. Klein et al ${ }^{133}$ reported that $\mathrm{SVCAM}-1$ and $\mathrm{TNF} \alpha$ are associated with higher odds of developing more severe DR in patients with renal disease and PDR. Other evidence suggests that anti-VEGF treatments have no effect on the cytokines other than VEGF levels in intraocular fluids. ${ }^{130-132}$

The available evidence therefore implies that targeting VEGF alone or VEGF-independent pathways in isolation may not adequately block the increased permeability associated with diabetes and hyperglycaemia.

A combination approach may be necessary in some cases. Steroids and anti-VEGF may have complementary and additive effects on retinal vascular permeability. This follows from the evidence of Nehme and Edelman ${ }^{126}$ on the effect of dexamethasone on REC and pericyte permeability, and the reports from Felinski, 101,128 in concert with the anti-VEGF trials. The concept of combination pharmacotherapy in DMO has been given further impetus by preliminary results from our laboratory, which show that a combination of dexamethasone and ranibizumab reduced REC permeability more than either agent alone in vitro. ${ }^{110}$

\section{Clinical evidence}

A few trials have evaluated the combination of bevacizumab with triamcinolone. ${ }^{134-137}$ Ahmadieh et al ${ }^{134}$ evaluated bevacizumab alone in comparison to bevacizumab and triamcinolone, and determined that there was no further improvement with the combination compared with bevacizumab alone. Sohelian et al 135,136 compared combination of $1.25 \mathrm{mg}$ bevacizumab and $2 \mathrm{mg}$ triamcinolone with bevacizumab alone and laser photocoagulation alone. Bevacizumab alone improved BCVA at 36 months, compared with either the combination or the laser alone group. ${ }^{135,136}$ Faghihi et al ${ }^{137}$ compared intravitreal bevacizumab $(1.25 \mathrm{mg})$ alone with combination of bevacizumab and focal laser, and determined at 6 months that both regimes had comparable vision improvement and that neither dosage was superior to the other. The outcomes reported by Faghihi et al ${ }^{137}$ that combinations of bevacizumab and focal laser photocoagulation induced earlier recovery of VA compared with bevacizumab monotherapy, although this was not confirmed by Soheilian et al. ${ }^{138}$ Sheth et al ${ }^{139}$ did not find any difference in DMO reduction or post injection VA in eyes treated with intravitreal triamcinolone vs dexamethasone and bevacizumab. However, that is most likely because of the short duration of the dexamethasone used, as well as the small sample size. ${ }^{139}$ This concept has been given further impetus by preliminary results from our laboratory, which show that a combination of dexamethasone and ranibizumab reduced REC permeability more than either agent alone in vitro. ${ }^{110}$ In the DRCRNet Study, ${ }^{43,52}$ intravitreal 0.5-mg ranibizumab or 4-mg triamcinolone combined with focal/ grid laser was compared with focal/grid laser alone for treatment of DMO. At 24 months, the mean change in the VA letter score from baseline was 3.7 letters greater (95\% CI: -0.4 to +7.7$)$ in the ranibizumab plus prompt laser group, 5.8 letters greater in the ranibizumab plus deferred laser group ( $95 \%$ CI: +1.9 to +9.8 ) and 1.5 letters worse in the triamcinolone plus prompt laser group (95\% CI: -5.5 to +2.4$).{ }^{36}$ These VA changes were associated with parallel reductions in CRT as measured with OCT. ${ }^{36}$ Combination of dexamethasone implant with laser photocoagulation has been reported to result in more reduction in macular oedema and greater BCVA improvement up to 9 months compared with either agent on its own. ${ }^{140}$ No significant difference was noted at 12 months in the number of eyes that gained 10 letters or more, however.

\section{The way forward}

It is possible that an initial combination of dexamethasone and anti-VEGF therapy (ranibizumab or aflibercept) will allow a faster VA rise to the plateau than achieved with anti-VEGF monotherapy, may induce a longer remission of $\mathrm{DMO}$, and more permanently modulate the recurrence of DMO than after either agent on its own. This is important as complete dryness of the macular is only achieved in about $50-75 \%$ of eyes treated with anti-VEGF 
monotherapy. Furthermore, such a combination will reduce potential systemic adverse events as may be associated with frequent anti-VEGF therapies. As the effect of the dexamethasone implant only lasts

3-6 months, any associated IOP rise is short-lived. The longer-acting steroid, fluocinolone may also have a role in combination with anti-VEGF therapies especially in eyes that are pseudophakic. This follows from the fact that fluocinolone is more effective in eyes with longer duration of DMO than those with more recent onset. This is despite the side-effect profile of steroids including cataracts, and increased IOP. Potentially, if such a combination works, only one or two dexamethasone implant injections will be required, but at the same time reducing the frequency of intravitreal anti-VEGF injections.

Macular laser photocoagulation (focal) applied after treatment with anti-VEGF and/or dexamethasone implant (deferred laser) allows lower energy laser applications thus reducing collateral damage. This, as seen in the DRCRnet studies, gives better outcomes and results in reduction of the number of intravitreal injections required, with increased BCVA gain (2.9 letters better at month 36). ${ }^{52}$

In the future, mTOR inhibition by subconjuctival or intravitreal sirolimus, or inhibition of Ang-2 alongside anti-VEG therapies may also more result in significant benefit in DR. For the anti-Ang-2 drug, the mode of delivery will, however, depend on the particular properties.

Similarly, other drugs that may interfere with any of the mechanisms in the development of DR, for example, benfotiamine are worth exploring as adjuncts to other therapies in DMO.

Fovista is an anti-platelet-derived growth factor agent currently under development as an intravitreal agent for the treatment of neovascular age-related macular degeneration in combination of anti-VEGF drugs. ${ }^{141}$ At the present time, it is not envisaged that it will have a role in the treatment of $\mathrm{DMO}$, until it is shown to be unlikely to induce more pericyte loss in the diabetic retina. Furthermore, systemic platelet-derived growth factor-B was not found to be significantly upregulated in patients with DMO when compared with normal individuals and the significant upregulation in neovascular age-related macular degeneration. ${ }^{142}$

Further elucidation of the cellular mechanisms underlying increased permeability in diabetes and hyperglycaemia, and the effects of different pharmacologic agents and their interactions are required. Similarly, cellular and physiological changes in the choroidal vasculature in diabetes require further investigation.

Systemic control of hyperglycaemia ( $\mathrm{Hb} \mathrm{A} 1 \mathrm{C})$, blood pressure and serum lipids, as well as the addition fenofibrates and/or statins in diabetics cannot be over-emphasised as these have a significant effect on the fluid leakage in the macula. ${ }^{143-146}$

\section{Conclusion}

This review has evaluated the individual treatments available for $\mathrm{DMO}$, and discussed the rationale and potential for combination therapy in DMO. Systemic factors including blood sugar, blood pressure, and lipids cannot be over-emphasised.

The ideal treatment for DMO should improve vision and morphological changes in the macular (eg, reduce macular oedema) for a significant duration, reduce adverse events, reduce treatment burden and costs, and be well tolerated by patients. Laser photocoagulation is of limited use in centre-involving $\mathrm{DMO}$, and requires augmentation in eyes where the foveal centre is threatened. No current individual treatment modality in $\mathrm{DMO}$ results in a completely dry macula in most cases.

This is understandable as there are multiple mechanisms including VEGF pathway, and the non-VEGF inflammation, which becomes more important in the chronic stages of DMO. Eyes with chronic DMO are more likely to befit from intravitreal steroid therapy. A combination of anti-VEGF therapies with steroids will provide more optimal pharmacotherapy, and may be supplemented with macular laser photocoagulation as necessary in individual cases. Newer agents in the future will further enhance efficacy of our treatments for DMO.

\section{Conflict of interest}

WMK Amoaku has provided consultancy services to Alcon, Allergan, Bayer, Novartis and Thrombogenics. He has received travel grants from Allergan, Bayer and Novartis, and honoraria for lectures from Allergan, Novartis. He has participated in clinical trials for which his institution has received funding from Allergan, Novartis and Pfizer. His institution has further received research grants from Allergan and Novartis for nonclinical studies, and CentreVue (Italy) for clinical studies. The remaining authors declare no conflict of interest.

\section{References}

1 Resnikoff S, Pascolini D, Etya'ale D, Kocur I, Pararajasegaram R, Pokharel GP et al. Global data on visual impairment in the year 2002. Bull World Health Organ 2004; 82(11): 844-851.

2 King H, Aubert RE, Herman WH. Global burden of diabetes, 1995-2025: prevalence, numerical estimates, and projections. Diabetes Care 1998; 21(9): 1414-1431.

3 Guariguata L, Whiting DR, Hambleton I, Beagley J, Linnenkamp U, Shaw JE. Global estimates of diabetes 
prevalence for 2013 and projections for 2035. Diabetes Res Clin Pract 2014; 103(2): 137-149.

4 Ferris 3rd FL, Chew EY, Hoogwerf BJ. Serum lipids and diabetic retinopathy. Early Treatment Diabetic Retinopathy Study Research Group. Diabetes Care 1996; 19(11): 1291-1293.

5 Klein R, Marino EK, Kuller LH, Polak JF, Tracy RP, Gottdiener JS et al. The relation of atherosclerotic cardiovascular disease to retinopathy in people with diabetes in the Cardiovascular Health Study. $\mathrm{Br} \mathrm{J}$ Ophthalmol 2002; 86(1): 84-90.

6 Hidayat AA, Fine BS. Diabetic choroidopathy. Light and electron microscopic observations of seven cases. Ophthalmology 1985; 92(4): 512-522.

7 Fryczkowski AW, Hodes BL, Walker J. Diabetic choroidal and iris vasculature scanning electron microscopy findings. Int Ophthalmol 1989; 13(4): 269-279.

8 Bischoff PM, Flower RW. Ten years experience with choroidal angiography using indocyanine green dye: a new routine examination or an epilogue? Doc Ophthalmol 1985; 60(3): 235-291.

9 Ishibashi T, Murata T, Kohno T, Ohnishi Y, Inomata H. Peripheral choriovitreal neovascularization in proliferative diabetic retinopathy: histopathologic and ultrastructural study. Ophthalmologica 1999; 213(3): 154-158.

10 Ciulla TA, Amador AG, Zinman B. Diabetic retinopathy and diabetic macular edema: pathophysiology, screening, and novel therapies. Diabetes Care 2003; 26(9): 2653-2664.

11 Mohr S. Potential new strategies to prevent the development of diabetic retinopathy. Expert Opin Investig Drugs 2004; 13(3): 189-198.

12 Miyamoto K, Ogura Y. Pathogenetic potential of leukocytes in diabetic retinopathy. Semin Ophthalmol 1999; 14(4): 233-239.

13 Bhavsar AR. Diabetic retinopathy: the latest in current management. Retina 2006; 26(6 Suppl): S71-S79.

14 Bhavsar AR, Tornambe PE. 25 years of progress in the treatment of retinal diseases: where we have been, where we are now, and where we will be. Retina 2006; 26(6 Suppl): S1-S6.

15 Klein R, Klein BE, Moss SE, Cruickshanks KJ. The Wisconsin Epidemiologic Study of Diabetic Retinopathy: XVII. The 14-year incidence and progression of diabetic retinopathy and associated risk factors in type 1 diabetes. Ophthalmology 1998; 105(10): 1801-1815.

16 Bhagat N, Grigorian RA, Tutela A, Zarbin MA. Diabetic macular edema: pathogenesis and treatment. Surv Ophthalmol 2009; 54(1): 1-32.

17 Klaassen I, Van Noorden CJ, Schlingemann RO. Molecular basis of the inner blood-retinal barrier and its breakdown in diabetic macular edema and other pathological conditions. Prog Retin Eye Res 2013; 34: 19-48.

18 Johnson MW. Etiology and treatment of macular edema. Am J Ophthalmol 2009; 147(1): 11-21 e11.

19 Joussen AM, Poulaki V, Le ML, Koizumi K, Esser C, Janicki $\mathrm{H}$ et al. A central role for inflammation in the pathogenesis of diabetic retinopathy. FASEB J 2004; 18(12): 1450-1452.

20 Kaji Y, Usui T, Ishida S, Yamashiro K, Moore TC, Moore J et al. Inhibition of diabetic leukostasis and blood-retinal barrier breakdown with a soluble form of a receptor for advanced glycation end products. Invest Ophthalmol Vis Sci 2007; 48(2): 858-865.
21 Min JK, Cho YL, Choi JH, Kim Y, Kim JH, Yu YS et al. Receptor activator of nuclear factor (NF)-kappaB ligand (RANKL) increases vascular permeability: impaired permeability and angiogenesis in eNOS-deficient mice. Blood 2007; 109(4): 1495-1502.

22 Kim YM, Kim YM, Lee YM, Kim HS, Kim JD, Choi Y et al. TNF-related activation-induced cytokine (TRANCE) induces angiogenesis through the activation of Src and phospholipase C (PLC) in human endothelial cells. J Biol Chem 2002; 277(9): 6799-6805.

23 Clermont AC, Cahill M, Salti H, Rook SL, Rask-Madsen C, Goddard L et al. Hepatocyte growth factor induces retinal vascular permeability via MAP-kinase and PI-3 kinase without altering retinal hemodynamics. Invest Ophthalmol Vis Sci 2006; 47(6): 2701-2708.

24 Haynes BF, Liao HX, Patton KL. The transmembrane hyaluronate receptor (CD44): multiple functions, multiple forms. Cancer Cells 1991; 3(9): 347-350.

25 Trochon V, Mabilat C, Bertrand P, Legrand Y, Smadja-Joffe F, Soria C et al. Evidence of involvement of CD44 in endothelial cell proliferation, migration and angiogenesis in vitro. Int $\mathrm{J}$ Cancer 1996; 66(5): 664-668.

26 Schmidt AM, Hori O, Chen JX, Li JF, Crandall J, Zhang J et al. Advanced glycation endproducts interacting with their endothelial receptor induce expression of vascular cell adhesion molecule-1 (VCAM-1) in cultured human endothelial cells and in mice. A potential mechanism for the accelerated vasculopathy of diabetes. J Clin Invest 1995; 96(3): 1395-1403.

27 Schram MT, Chaturvedi N, Schalkwijk C, Giorgino F, Ebeling $\mathrm{P}$, Fuller JH et al. Vascular risk factors and markers of endothelial function as determinants of inflammatory markers in type 1 diabetes: the EURODIAB Prospective Complications Study. Diabetes Care 2003; 26(7): 2165-2173.

28 Adamis AP. Is diabetic retinopathy an inflammatory disease? Br J Ophthalmol 2002; 86(4): 363-365.

29 Photocoagulation for diabetic macular edema. Early Treatment Diabetic Retinopathy Study report number 1. Early Treatment Diabetic Retinopathy Study research group. Arch Ophthalmol 1985; 103(12): 1796-1806.

30 Treatment techniques and clinical guidelines for photocoagulation of diabetic macular edema. Early Treatment Diabetic Retinopathy Study Report Number 2. Early Treatment Diabetic Retinopathy Study Research Group. Ophthalmology 1987; 94(7): 761-774.

31 Lee CM, Olk RJ. Modified grid laser photocoagulation for diffuse diabetic macular edema. Long-term visual results. Ophthalmology 1991; 98(10): 1594-1602.

32 Schatz H, Madeira D, McDonald HR, Johnson RN. Progressive enlargement of laser scars following grid laser photocoagulation for diffuse diabetic macular edema. Arch Ophthalmol 1991; 109(11): 1549-1551.

33 Rutledge BK, Wallow IH, Poulsen GL. Sub-pigment epithelial membranes after photocoagulation for diabetic macular edema. Arch Ophthalmol 1993; 111(5): 608-613.

34 Writing Committee for the Diabetic Retinopathy Clinical Research N, Fong DS, Strauber SF, Aiello LP, Beck RW, Callanan DG et al. Comparison of the modified Early Treatment Diabetic Retinopathy Study and mild macular grid laser photocoagulation strategies for diabetic macular edema. Arch Ophthalmol 2007; 125(4): 469-480.

35 Vujosevic S, Martini F, Convento E, Longhin E, Kotsafti O, Parrozzani $\mathrm{R}$ et al. Subthreshold laser therapy for diabetic 
macular edema: metabolic and safety issues. Curr Med Chem 2013; 20(26): 3267-3271.

36 Elman MJ, Bressler NM, Qin H, Beck RW, Ferris III FL, Friedman SM et al. Expanded 2-year follow-up of ranibizumab plus prompt or deferred laser or triamcinolone plus prompt laser for diabetic macular edema. Ophthalmology 2011; 118(4): 609-614.

37 Massin P, Bandello F, Garweg JG, Hansen LL, Harding SP, Larsen $\mathrm{M}$ et al. Safety and efficacy of ranibizumab in diabetic macular edema (RESOLVE Study): a 12-month, randomized, controlled, double-masked, multicenter phase II study. Diabetes Care 2010; 33(11): 2399-2405.

38 Mitchell P, Bandello F, Schmidt-Erfurth U, Lang GE, Massin P, Schlingemann RO et al. The RESTORE study: ranibizumab monotherapy or combined with laser versus laser monotherapy for diabetic macular edema. Ophthalmology 2011; 118(4): 615-625.

39 Nguyen QD, Brown DM, Marcus DM, Boyer DS, Patel S, Feiner L et al. Ranibizumab for diabetic macular edema: results from 2 phase III randomized trials: RISE and RIDE. Ophthalmology 2012; 119(4): 789-801.

40 Rajendram R, Fraser-Bell S, Kaines A, Michaelides M, Hamilton RD, Esposti SD et al. A 2-year prospective randomized controlled trial of intravitreal bevacizumab or laser therapy (BOLT) in the management of diabetic macular edema: 24-month data: report 3. Arch Ophthalmol 2012; 130(8): 972-979.

41 Korobelnik JF, Do DV, Schmidt-Erfurth U, Boyer DS, Holz FG, Heier JS et al. Intravitreal Aflibercept for Diabetic Macular Edema. Ophthalmology 2014; 121(11): 2247-2254.

42 Kuppermann BD, Blumenkranz MS, Haller JA, Williams GA, Weinberg DV, Chou C et al. Randomized controlled study of an intravitreous dexamethasone drug delivery system in patients with persistent macular edema. Arch Ophthalmol 2007; 125(3): 309-317.

43 Diabetic Retinopathy Clinical Research N, Elman MJ, Aiello LP, Beck RW, Bressler NM, Bressler SB et al. Randomized trial evaluating ranibizumab plus prompt or deferred laser or triamcinolone plus prompt laser for diabetic macular edema. Ophthalmology 2010; 117(6): 1064-1077 e1035.

44 Boyer DS, Faber D, Gupta S, Patel SS, Tabandeh H, Li XY et al. Dexamethasone intravitreal implant for treatment of diabetic macular edema in vitrectomized patients. Retina 2011; 31(5): 915-923.

45 Boyer DS, Yoon YH, Belfort Jr R, Bandello F, Maturi RK, Augustin AJ et al. Three-year, randomized, sham-controlled trial of dexamethasone intravitreal implant in patients with diabetic macular edema. Ophthalmology 2014; 121(10): 1904-1914.

46 Pearson PA, Comstock TL, Ip M, Callanan D, Morse LS, Ashton $\mathrm{P}$ et al. Fluocinolone acetonide intravitreal implant for diabetic macular edema: a 3-year multicenter, randomized, controlled clinical trial. Ophthalmology 2011; 118(8): 1580-1587.

47 Campochiaro PA, Brown DM, Pearson A, Ciulla T, Boyer D, Holz FG et al. Long-term benefit of sustained-delivery fluocinolone acetonide vitreous inserts for diabetic macular edema. Ophthalmology 2011; 118(4): 626-635 e622.

48 Gillies MC, Sutter FK, Simpson JM, Larsson J, Ali H, Zhu M. Intravitreal triamcinolone for refractory diabetic macular edema: two-year results of a double-masked, placebocontrolled, randomized clinical trial. Ophthalmology 2006; 113 (9): 1533-1538.
49 Munir WM, Pulido JS, Sharma MC, Buerk BM. Intravitreal triamcinolone for treatment of complicated proliferative diabetic retinopathy and proliferative vitreoretinopathy. Can J Ophthalmol 2005; 40(5): 598-604.

50 Haller JA, Kuppermann BD, Blumenkranz MS, Williams GA, Weinberg DV, Chou C et al. Randomized controlled trial of an intravitreous dexamethasone drug delivery system in patients with diabetic macular edema. Arch Ophthalmol 2010; 128(3): 289-296.

51 Kuppermann BD, Chou C, Weinberg DV, Whitcup SM, Haller JA, Blumenkranz MS et al. Intravitreous dexamethasone effects on different patterns of diabetic macular edema. Arch Ophthalmol 2010; 128(5): 642-643.

52 Diabetic Retinopathy Clinical Research N, Elman MJ, Qin H, Aiello LP, Beck RW, Bressler NM et al. Intravitreal ranibizumab for diabetic macular edema with prompt versus deferred laser treatment: three-year randomized trial results. Ophthalmology 2012; 119(11): 2312-2318.

53 Cunningham Jr ET, Adamis AP, Altaweel M, Aiello LP, Bressler NM, D'Amico DJ et al. A phase II randomized double-masked trial of pegaptanib, an anti-vascular endothelial growth factor aptamer, for diabetic macular edema. Ophthalmology 2005; 112(10): 1747-1757.

54 Sultan MB, Zhou D, Loftus J, Dombi T, Ice KSMacugen Study G. A phase 2/3, multicenter, randomized, doublemasked, 2-year trial of pegaptanib sodium for the treatment of diabetic macular edema. Ophthalmology 2011; 118(6): 1107-1118.

55 Michaelides M, Kaines A, Hamilton RD, Fraser-Bell S, Rajendram R, Quhill F et al. A prospective randomized trial of intravitreal bevacizumab or laser therapy in the management of diabetic macular edema (BOLT study) 12month data: report 2. Ophthalmology 2010; 117(6): 1078-1086 e1072.

56 Lam DS, Lai TY, Lee VY, Chan CK, Liu DT, Mohamed S et al. Efficacy of 1.25 MG versus 2.5 MG intravitreal bevacizumab for diabetic macular edema: six-month results of a randomized controlled trial. Retina 2009; 29(3): 292-299.

57 Ip MS, Bressler SB, Antoszyk AN, Flaxel CJ, Kim JE, Friedman $\mathrm{SM}$ et al. A randomized trial comparing intravitreal triamcinolone and focal/grid photocoagulation for diabetic macular edema: baseline features. Retina 2008; 28(7): 919-930.

58 Diabetic Retinopathy Clinical Research N. A randomized trial comparing intravitreal triamcinolone acetonide and focal/grid photocoagulation for diabetic macular edema. Ophthalmology 2008; 115(9): 1447-1449 1449 e1441-1410.

59 Diabetic Retinopathy Clinical Research N, Beck RW, Edwards AR, Aiello LP, Bressler NM, Ferris F et al. Threeyear follow-up of a randomized trial comparing focal/grid photocoagulation and intravitreal triamcinolone for diabetic macular edema. Arch Ophthalmol 2009; 127(3): 245-251.

60 Gillies MC, Lim LL, Campain A, Quin GJ, Salem W, Li J et al. A randomized clinical trial of intravitreal bevacizumab versus intravitreal dexamethasone for diabetic macular edema: The BEVORDEX Study. Ophthalmology 2014; 121 (12): 2473-2481.

61 Oh H, Takagi H, Takagi C, Suzuma K, Otani A, Ishida K et al. The potential angiogenic role of macrophages in the formation of choroidal neovascular membranes. Invest Ophthalmol Vis Sci 1999; 40(9): 1891-1898. 
62 Mandriota SJ, Pyke C, Di Sanza C, Quinodoz P, Pittet B, Pepper MS. Hypoxia-inducible angiopoietin-2 expression is mimicked by iodonium compounds and occurs in the rat brain and skin in response to systemic hypoxia and tissue ischemia. Am J Pathol 2000; 156(6): 2077-2089.

63 Hammes HP, Lin J, Wagner P, Feng Y, Vom Hagen F, Krzizok $\mathrm{T}$ et al. Angiopoietin-2 causes pericyte dropout in the normal retina: evidence for involvement in diabetic retinopathy. Diabetes 2004; 53(4): 1104-1110.

64 Yao D, Taguchi T, Matsumura T, Pestell R, Edelstein D, Giardino I et al. High glucose increases angiopoietin-2 transcription in microvascular endothelial cells through methylglyoxal modification of mSin3A. J Biol Chem 2007; 282(42): 31038-31045.

65 Fiedler U, Scharpfenecker M, Koidl S, Hegen A, Grunow V, Schmidt JM et al. The Tie-2 ligand angiopoietin-2 is stored in and rapidly released upon stimulation from endothelial cell Weibel-Palade bodies. Blood 2004; 103(11): 4150-4156.

66 Patel JI, Hykin PG, Gregor ZJ, Boulton M, Cree IA. Angiopoietin concentrations in diabetic retinopathy. $\mathrm{Br} J$ Ophthalmol 2005; 89(4): 480-483.

67 Peters S, Cree IA, Alexander R, Turowski P, Ockrim Z, Patel J et al. Angiopoietin modulation of vascular endothelial growth factor: Effects on retinal endothelial cell permeability. Cytokine 2007; 40(2): 144-150.

68 Pfister F, Wang Y, Schreiter K, vom Hagen F, Altvater K, Hoffmann $S$ et al. Retinal overexpression of angiopoietin-2 mimics diabetic retinopathy and enhances vascular damages in hyperglycemia. Acta diabetologica 2010; 47(1): 59-64

69 Hackett SF, Ozaki H, Strauss RW, Wahlin K, Suri C, Maisonpierre $\mathrm{P}$ et al. Angiopoietin 2 expression in the retina: upregulation during physiologic and pathologic neovascularization. J Cell Physiol 2000; 184(3): 275-284.

70 Watanabe D, Suzuma K, Suzuma I, Ohashi H, Ojima T, Kurimoto $\mathrm{M}$ et al. Vitreous levels of angiopoietin 2 and vascular endothelial growth factor in patients with proliferative diabetic retinopathy. Am J Ophthalmol 2005; 139(3): 476-481.

71 Rangasamy S, Srinivasan R, Maestas J, McGuire PG, Das A. A potential role for angiopoietin 2 in the regulation of the blood-retinal barrier in diabetic retinopathy. Invest Ophthalmol Vis Sci 2011; 52(6): 3784-3791.

72 Fiedler U, Reiss Y, Scharpfenecker M, Grunow V, Koidl S, Thurston G et al. Angiopoietin-2 sensitizes endothelial cells to TNF-alpha and has a crucial role in the induction of inflammation. Nat Med 2006; 12(2): 235-239.

73 You QY, Zhuge FY, Zhu QQ, Si XW. Effects of laser photocoagulation on serum angiopoietin-1, angiopoietin-2, angiopoietin-1/angiopoietin-2 ratio, and soluble angiopoietin receptor Tie-2 levels in type 2 diabetic patients with proliferative diabetic retinopathy. Int J Ophthalmol 2014; 7(4): 648-653.

74 Lip PL, Chatterjee S, Caine GJ, Hope-Ross M, Gibson J, Blann AD et al. Plasma vascular endothelial growth factor, angiopoietin-2, and soluble angiopoietin receptor tie-2 in diabetic retinopathy: effects of laser photocoagulation and angiotensin receptor blockade. Br J Ophthalmol 2004; 88(12): 1543-1546.

75 Hammes HP, Du X, Edelstein D, Taguchi T, Matsumura T, $\mathrm{Ju} \mathrm{Q}$ et al. Benfotiamine blocks three major pathways of hyperglycemic damage and prevents experimental diabetic retinopathy. Nat Med 2003; 9(3): 294-299.
76 Yadav UC, Kalariya NM, Srivastava SK, Ramana KV. Protective role of benfotiamine, a fat-soluble vitamin B1 analogue, in lipopolysaccharide-induced cytotoxic signals in murine macrophages. Free Radic Biol Med 2010; 48(10): 1423-1434.

77 Shoeb M, Ramana KV. Anti-inflammatory effects of benfotiamine are mediated through the regulation of the arachidonic acid pathway in macrophages. Free Radic Biol Med 2012; 52(1): 182-190.

78 Kim I, Moon SO, Koh KN, Kim H, Uhm CS, Kwak HJ et al. Molecular cloning, expression, and characterization of angiopoietin-related protein. angiopoietin-related protein induces endothelial cell sprouting. J Biol Chem 1999; 274(37): 26523-26528.

$79 \mathrm{Xu} \mathrm{Y,} \mathrm{Yu} \mathrm{Q.} \mathrm{Angiopoietin-1} \mathrm{unlike} \mathrm{angiopoietin-2,} \mathrm{is}$ incorporated into the extracellular matrix via its linker peptide region. J Biol Chem 2001; 276(37): 34990-34998.

80 Kim I, Kim HG, So JN, Kim JH, Kwak HJ, Koh GY. Angiopoietin-1 regulates endothelial cell survival through the phosphatidylinositol 3'-Kinase/Akt signal transduction pathway. Circ Res 2000; 86(1): 24-29.

81 Joussen AM, Poulaki V, Tsujikawa A, Qin W, Qaum T, $\mathrm{Xu} \mathrm{Q}$ et al. Suppression of diabetic retinopathy with angiopoietin-1. Am J Pathol 2002; 160(5): 1683-1693.

82 Kim I, Moon SO, Park SK, Chae SW, Koh GY. Angiopoietin-1 reduces VEGF-stimulated leukocyte adhesion to endothelial cells by reducing ICAM-1, VCAM-1, and E-selectin expression. Circ Res 2001; 89(6): 477-479.

83 Zeng $\mathrm{K}$, Ming J, Yang N, Wang J, Yu X, Song Y et al. Taurine prevents high glucose-induced angiopoietin-2/tie2 system alterations and apoptosis in retinal microvascular pericytes. Mol Cell Biochem 2014; 396(1-2): 239-248.

84 Napoli KL, Taylor PJ. From beach to bedside: history of the development of sirolimus. Ther Drug Monit 2001; 23(5): 559-586.

85 Zhong H, Chiles K, Feldser D, Laughner E, Hanrahan C, Georgescu MM et al. Modulation of hypoxia-inducible factor 1alpha expression by the epidermal growth factor/ phosphatidylinositol 3-kinase/PTEN/AKT/FRAP pathway in human prostate cancer cells: implications for tumor angiogenesis and therapeutics. Cancer Res 2000; 60(6): 1541-1545.

86 Abraham RT. mTOR as a positive regulator of tumor cell responses to hypoxia. Curr Top Microbiol Immunol 2004; 279: 299-319.

87 Majumder PK, Febbo PG, Bikoff R, Berger R, Xue Q, McMahon LM et al. mTOR inhibition reverses Aktdependent prostate intraepithelial neoplasia through regulation of apoptotic and HIF-1-dependent pathways. Nat Med 2004; 10(6): 594-601.

88 Hudson CC, Liu M, Chiang GG, Otterness DM, Loomis DC, Kaper $\mathrm{F}$ et al. Regulation of hypoxia-inducible factor 1alpha expression and function by the mammalian target of rapamycin. Mol Cell Biol 2002; 22(20): 7004-7014.

89 Brugarolas JB, Vazquez F, Reddy A, Sellers WR, Kaelin Jr WG TSC2 regulates VEGF through mTOR-dependent and -independent pathways. Cancer cell 2003; 4(2): 147-158.

90 Dutcher JP. Mammalian target of rapamycin inhibition. Clin Cancer Res 2004; 10(18 Pt 2): 6382S-6387S.

91 Rokaw MD, West M, Johnson JP. Rapamycin inhibits protein kinase $\mathrm{C}$ activity and stimulates $\mathrm{Na}+$ transport in A6 cells. J Biol Chem 1996; 271(50): 32468-32473. 
92 Attur MG, Patel R, Thakker G, Vyas P, Levartovsky D, Patel $P$ et al. Differential anti-inflammatory effects of immunosuppressive drugs: cyclosporin, rapamycin and FK-506 on inducible nitric oxide synthase, nitric oxide, cyclooxygenase-2 and PGE2 production. Inflamm Res 2000; 49(1): 20-26.

93 Nuhrenberg TG, Voisard R, Fahlisch F, Rudelius M, Braun J, Gschwend J et al. Rapamycin attenuates vascular wall inflammation and progenitor cell promoters after angioplasty. FASEB J 2005; 19(2): 246-248.

94 Dugel PU, Blumenkranz MS, Haller JA, Williams GA, Solley WA, Kleinman DM et al. A randomized, doseescalation study of subconjunctival and intravitreal injections of sirolimus in patients with diabetic macular edema. Ophthalmology 2012; 119(1): 124-131.

95 Krishnadev N, Forooghian F, Cukras C, Wong W, Saligan L, Chew EY et al. Subconjunctival sirolimus in the treatment of diabetic macular edema. Graefes Arch Clin Exp Ophthalmol 2011; 249(11): 1627-1633.

96 Vitale S, Maguire MG, Murphy RP, Hiner CJ, Rourke L, Sackett $C$ et al. Clinically significant macular edema in type I diabetes. Incidence and risk factors. Ophthalmology 1995; 102(8): 1170-1176.

97 Mitic LL, Anderson JM. Molecular architecture of tight junctions. Annu Rev Physiol 1998; 60: 121-142.

98 Dejana E, Spagnuolo R, Bazzoni G. Interendothelial junctions and their role in the control of angiogenesis, vascular permeability and leukocyte transmigration. Thromb Haemost 2001; 86(1): 308-315.

99 Abbott NJ, Ronnback L, Hansson E. Astrocyte-endothelial interactions at the blood-brain barrier. Nat Rev Neurosci 2006; 7(1): 41-53.

100 Edelman JL, Lutz D, Castro MR. Corticosteroids inhibit VEGF-induced vascular leakage in a rabbit model of bloodretinal and blood-aqueous barrier breakdown. Exp Eye Res 2005; 80(2): 249-258.

101 Felinski EA, Antonetti DA. Glucocorticoid regulation of endothelial cell tight junction gene expression: novel treatments for diabetic retinopathy. Curr Eye Res 2005; 30(11): 949-957.

102 Antonetti DA, Barber AJ, Khin S, Lieth E, Tarbell JM, Gardner TW. Vascular permeability in experimental diabetes is associated with reduced endothelial occludin content: vascular endothelial growth factor decreases occludin in retinal endothelial cells. Penn State Retina Research Group. Diabetes 1998; 47(12): 1953-1959.

103 Harhaj NS, Felinski EA, Wolpert EB, Sundstrom JM, Gardner TW, Antonetti DA. VEGF activation of protein kinase $C$ stimulates occludin phosphorylation and contributes to endothelial permeability. Invest Ophthalmol Vis Sci 2006; 47(11): 5106-5115.

104 Giebel SJ, Menicucci G, McGuire PG, Das A. Matrix metalloproteinases in early diabetic retinopathy and their role in alteration of the blood-retinal barrier. Lab Invest 2005; 85(5): 597-607.

105 Murakami T, Felinski EA, Antonetti DA. Occludin phosphorylation and ubiquitination regulate tight junction trafficking and vascular endothelial growth factor-induced permeability. J Biol Chem 2009; 284(31): 21036-21046.

106 Saishin Y, Saishin Y, Takahashi K, Melia M, Vinores SA, Campochiaro PA. Inhibition of protein kinase $\mathrm{C}$ decreases prostaglandin-induced breakdown of the blood-retinal barrier. J Cell Physiol 2003; 195(2): 210-219.

107 Orlova VV, Economopoulou M, Lupu F, Santoso S, Chavakis T. Junctional adhesion molecule-C regulates vascular endothelial permeability by modulating VE-cadherin-mediated cell-cell contacts. J Exp Med 2006; 203(12): 2703-2714.

108 Weber C, Fraemohs L, Dejana E. The role of junctional adhesion molecules in vascular inflammation. Nat Rev Immunol 2007; 7(6): 467-477.

109 Ozaki H, Ishii K, Horiuchi H, Arai H, Kawamoto T, Okawa $\mathrm{K}$ et al. Cutting edge: combined treatment of TNF-alpha and IFN-gamma causes redistribution of junctional adhesion molecule in human endothelial cells. J Immunol 1999; 163(2): 553-557.

110 Saker S, Stewart EA, Browning AC, Allen CL, Amoaku WM. The effect of hyperglycaemia on permeability and the expression of junctional complex molecules in human retinal and choroidal endothelial cells. Exp Eye Res 2014; 121: 161-167.

111 Campochiaro PA. Retinal and choroidal neovascularization. J Cell Physiol 2000; 184(3): 301-310.

112 Lehmann I, Brylla E, Sittig D, Spanel-Borowski K, Aust G. Microvascular endothelial cells differ in their basal and tumour necrosis factor-alpha-regulated expression of adhesion molecules and cytokines. J Vasc Res 2000; 37(5): 408-416.

113 Mooradian AD. Central nervous system complications of diabetes mellitus-a perspective from the bloodbrain barrier. Brain Res Brain Res Rev 1997; 23(3): 210-218.

114 Omi H, Okayama N, Shimizu M, Okouchi M, Ito S, Fukutomi T et al. Participation of high glucose concentrations in neutrophil adhesion and surface expression of adhesion molecules on cultured human endothelial cells: effect of antidiabetic medicines. J Diabetes Complications 2002; 16(3): 201-208.

115 Morigi M, Angioletti S, Imberti B, Donadelli R, Micheletti G, Figliuzzi $\mathrm{M}$ et al. Leukocyte-endothelial interaction is augmented by high glucose concentrations and hyperglycemia in a NF-kB-dependent fashion. J Clin Invest 1998; 101(9): 1905-1915.

116 Booth G, Stalker TJ, Lefer AM, Scalia R. Mechanisms of amelioration of glucose-induced endothelial dysfunction following inhibition of protein kinase $\mathrm{C}$ in vivo. Diabetes 2002; 51(5): 1556-1564.

117 Koch AE, Halloran MM, Haskell CJ, Shah MR, Polverini PJ. Angiogenesis mediated by soluble forms of E-selectin and vascular cell adhesion molecule-1. Nature 1995; 376(6540): 517-519.

118 Lu M, Perez VL, Ma N, Miyamoto K, Peng HB, Liao JK et al. VEGF increases retinal vascular ICAM-1 expression in vivo. Invest Ophthalmol Vis Sci 1999; 40(8): 1808-1812.

119 Yoshimura T, Sonoda KH, Sugahara M, Mochizuki Y, Enaida $\mathrm{H}$, Oshima $\mathrm{Y}$ et al. Comprehensive analysis of inflammatory immune mediators in vitreoretinal diseases. PLoS One 2009; 4(12): e8158.

120 Funatsu H, Yamashita H, Ikeda T, Nakanishi Y, Kitano S, Hori S. Angiotensin II and vascular endothelial growth factor in the vitreous fluid of patients with diabetic macular edema and other retinal disorders. Am J Ophthalmol 2002; 133(4): 537-543.

121 Funatsu H, Yamashita H, Sakata K, Noma H, Mimura T, Suzuki M et al. Vitreous levels of vascular endothelial 
growth factor and intercellular adhesion molecule 1 are related to diabetic macular edema. Ophthalmology 2005; 112(5): 806-816.

122 Funatsu H, Yamashita H, Shimizu E, Kojima R, Hori S. Relationship between vascular endothelial growth factor and interleukin-6 in diabetic retinopathy. Retina 2001; 21(5): 469-477.

123 Chibber R, Ben-Mahmud BM, Chibber S, Kohner EM. Leukocytes in diabetic retinopathy. Curr Diabetes Rev 2007; 3(1): 3-14.

124 Chibber R, Ben-Mahmud BM, Coppini D, Christ E, Kohner EM. Activity of the glycosylating enzyme, core 2 GlcNAc (beta1,6) transferase, is higher in polymorphonuclear leukocytes from diabetic patients compared with agematched control subjects: relevance to capillary occlusion in diabetic retinopathy. Diabetes 2000; 49(10): 1724-1730.

125 Chibber R, Ben-Mahmud BM, Mann GE, Zhang JJ, Kohner EM. Protein kinase $C$ beta2-dependent phosphorylation of core 2 GlcNAc-T promotes leukocyte-endothelial cell adhesion: a mechanism underlying capillary occlusion in diabetic retinopathy. Diabetes 2003; 52(6): 1519-1527.

126 Nehme A, Edelman J. Dexamethasone inhibits high glucose-, TNF-alpha-, and IL-1beta-induced secretion of inflammatory and angiogenic mediators from retinal microvascular pericytes. Invest Ophthalmol Vis Sci 2008; 49(5): 2030-2038.

127 Kleinman ME, Baffi JZ, Ambati J. The multifactorial nature of retinal vascular disease. Ophthalmologica 2010; 224(Suppl 1): 16-24.

128 Felinski EA, Cox AE, Phillips BE, Antonetti DA. Glucocorticoids induce transactivation of tight junction genes occludin and claudin-5 in retinal endothelial cells via a novel cis-element. Exp Eye Res 2008; 86(6): 867-878.

129 Stewart EA, Amoaku WM. The functional effects and expression of HGF and FGF in the choroid. Acta Ophthalmol 2014; 92: s293.

130 Roh MI, Kim HS, Song JH, Lim JB, Kwon OW. Effect of intravitreal bevacizumab injection on aqueous humor cytokine levels in clinically significant macular edema. Ophthalmology 2009; 116(1): 80-86.

131 Funk M, Schmidinger G, Maar N, Bolz M, Benesch T, Zlabinger GJ et al. Angiogenic and inflammatory markers in the intraocular fluid of eyes with diabetic macular edema and influence of therapy with bevacizumab. Retina 2010; 30(9): 1412-1419.

132 Sohn HJ, Han DH, Kim IT, Oh IK, Kim KH, Lee DY et al. Changes in aqueous concentrations of various cytokines after intravitreal triamcinolone versus bevacizumab for diabetic macular edema. Am J Ophthalmol 2011; 152(4): 686-694.

133 Klein BE, Knudtson MD, Tsai MY, Klein R. The relation of markers of inflammation and endothelial dysfunction to the prevalence and progression of diabetic retinopathy: Wisconsin epidemiologic study of diabetic retinopathy. Arch Ophthalmol 2009; 127(9): 1175-1182.

134 Ahmadieh H, Ramezani A, Shoeibi N, Bijanzadeh B, Tabatabaei A, Azarmina $\mathrm{M}$ et al. Intravitreal bevacizumab with or without triamcinolone for refractory diabetic macular edema; a placebo-controlled, randomized clinical trial. Graefes Arch Clin Exp Ophthalmol 2008; 246(4): 483-489.

135 Soheilian M, Garfami KH, Ramezani A, Yaseri M, Peyman GA. Two-year results of a randomized trial of intravitreal bevacizumab alone or combined with triamcinolone versus laser in diabetic macular edema. Retina 2012; 32(2): 314-321.

136 Soheilian M, Ramezani A, Bijanzadeh B, Yaseri M, Ahmadieh $\mathrm{H}$, Dehghan $\mathrm{MH}$ et al. Intravitreal bevacizumab (avastin) injection alone or combined with triamcinolone versus macular photocoagulation as primary treatment of diabetic macular edema. Retina 2007; 27(9): 1187-1195.

137 Faghihi H, Roohipoor R, Mohammadi SF, Hojat-Jalali K, Mirshahi A, Lashay A et al. Intravitreal bevacizumab versus combined bevacizumab-triamcinolone versus macular laser photocoagulation in diabetic macular edema. Eur J Ophthalmol 2008; 18(6): 941-948.

138 Soheilian M, Ramezani A, Obudi A, Bijanzadeh B, Salehipour M, Yaseri $\mathrm{M}$ et al. Randomized trial of intravitreal bevacizumab alone or combined with triamcinolone versus macular photocoagulation in diabetic macular edema. Ophthalmology 2009; 116(6): 1142-1150.

139 Sheth S, Rush R, Natarajan S, Gillies M. Intravitreal triamcinolone acetonide versus combined intravitreal bevacizumab and dexamethasone in diffuse diabetic macular oedema. Clin Experiment Ophthalmol 2011; 39(7): 673-681.

140 Callanan DG, Gupta S, Boyer DS, Ciulla TA, Singer MA, Kuppermann BD et al. Dexamethasone intravitreal implant in combination with laser photocoagulation for the treatment of diffuse diabetic macular edema. Ophthalmology 2013; 120(9): 1843-1851.

141 Boyer DS, Ophthotech Anti-PDGF in AMD Study Group. Combined Inhibition of Platelet Derived (PDGF) and Vascular Endothelial (VEGF) Growth Factors for the Treatment of Neovascular Age-Related Macular Degeneration (NV-AMD) - Results of a Phase 1 Study. ARVO Meet Abst 2009; 50(5): 1260.

142 Zehetner C, Kirchmair R, Neururer SB, Kralinger MT, Bechrakis NE, Kieselbach GF. Systemic upregulation of PDGF-B in patients with neovascular AMD. Invest Ophthalmol Vis Sci 2014; 55(1): 337-344.

143 Yau JW, Rogers SL, Kawasaki R, Lamoureux EL, Kowalski JW, Bek T et al. Global prevalence and major risk factors of diabetic retinopathy. Diabetes Care 2012; 35(3): 556-564.

144 Group AS, Group AES, Chew EY, Ambrosius WT, Davis MD, Danis RP et al. Effects of medical therapies on retinopathy progression in type 2 diabetes. $N$ Engl J Med 2010; 363(3): 233-244.

145 Wright AD, Dodson PM. Medical management of diabetic retinopathy: fenofibrate and ACCORD Eye studies. Eye (Lond) 2011; 25(7): 843-849.

146 Simo R, Hernandez C. Prevention and treatment of diabetic retinopathy: evidence from large, randomized trials. The emerging role of fenofibrate. Rev Recent Clin Trials 2012; 7(1): 71-80. 